\title{
Copper(I)-Catalyzed Disilylation of Alkylidene Malonates Employing a Lewis Base Activation Strategy
}

\author{
Christopher T. Clark, Jason F. Lake, Karl A. Scheidt* \\ Department of Chemistry, Northwestern University, 2145 Sheridan Road, Evanston, IL 60208

\section{Supporting Information}

General Information. All reactions were carried out under an atmosphere of argon or nitrogen in flame-dried glassware with magnetic stirring. THF, $\mathrm{Et}_{2} \mathrm{O}, \mathrm{CH}_{2} \mathrm{Cl}_{2}, \mathrm{DMF}$ and toluene were purified by passage through a bed of activated alumina. ${ }^{1}$ DMI was purified by distillation over calcium hydride under reduced pressure. HMPA and NMP were used from freshly opened bottles from Aldrich without further purification. Reagents were purified prior to use unless otherwise stated following the guidelines of Perrin and Armarego. ${ }^{2}$ Purification of reaction products was carried out by flash chromatography using EM Reagent silica gel 60 (230-400 mesh). Analytical thin layer chromatography was performed on EM Reagent $0.25 \mathrm{~mm}$ silica gel $60-\mathrm{F}$ plates. Visualization was accomplished with UV light and anisaldehyde, ceric ammonium nitrate stain, potassium permangenate, or phosphomolybic acid followed by heating. Melting points were obtained on a Melt-temp 3 instrument and are uncorrected. Infrared spectra were recorded on a Perkin Elmer 1600 series FT-IR spectrometer. ${ }^{1} \mathrm{H}-\mathrm{NMR}$ spectra were recorded on a Varian Inova $500(500 \mathrm{MHz})$ or Mercury $400(400 \mathrm{MHz})$ spectrometer and are reported in ppm using solvent as an internal standard $\left(\mathrm{CDCl}_{3}\right.$ at $\left.7.26 \mathrm{ppm}\right)$. Data are reported as (ap = apparent, $\mathrm{s}$ = singlet, $\mathrm{d}=$ doublet, $\mathrm{t}=$ triplet, $\mathrm{q}=$ quartet, $\mathrm{m}=$ multiplet, $\mathrm{b}=$ broad; coupling constant $(\mathrm{s})$ in $\mathrm{Hz}$; integration. Proton-decoupled ${ }^{13} \mathrm{C}-\mathrm{NMR}$ spectra were recorded on a Varian Inova 500 (125 $\mathrm{MHz})$ or Mercury $400(100 \mathrm{MHz})$ spectrometer and are reported in ppm using solvent as an internal standard $\left(\mathrm{CDCl}_{3}\right.$ at $\left.77.0 \mathrm{ppm}\right)$. Mass spectra data were obtained on a Varian 1200 Quadrupole Mass Spectronomer.

Copper(I) trifluoromethanesulfonate was prepared by a modified method of Kochi and coworkers. ${ }^{3}$ Alkylidene malonates were prepared according to the general procedure of Evans and co-workers. ${ }^{4}$

(1) Pangborn, A. B.; Giardello, M. A.; Grubbs, R. H.; Rosen, R. K.; Timmers, F. J. Organomettalics 1996, 15, 15181520.

(2) Perrin, D. D. and Armarego, W. L. Pruification of Laboratory Chemicals; 3rd ed., Pergamon Press, Oxford. 1988.

(3) (a) Salomon, R. G.; Kochi, J. K. J. Am. Chem. Soc. 1973, 95, 1889-1897. (b) Cohen, T.; Ruffner, R. J.; Shull, D. W.; Fogel, E. R.; Falck, J. R. Organic Syntheses; John Wiley \& Sons: New York; Vol. 6.

(4) Evans, D. A.; Rovis, T.; Kozlowski, M. C.; Downey, C. W.; Tedrow, J. S. J. Am. Chem. Soc.; 2000; 122, $9134-$

9142 and references cited therein. 


\section{General Experimental Procedure for the Copper(I)-Catalyzed Reaction:}

Copper(I) triflate benzene complex $(6.3 \mathrm{mg}, 0.0125 \mathrm{mmol}$ for aryl alkylidene malonates; $19 \mathrm{mg}$, $0.0375 \mathrm{mmol}$ for all others $)$ and an alkylidene malonate $(0.5 \mathrm{mmol})$ were added to a screw-cap test tube in a nitrogen-filled drybox. The test tube was taken out of the dry box and was put under a positive pressure of nitrogen. To this, toluene $(0.5 \mathrm{~mL}$, if applicable) and the ligand (4 equivalents with respect to copper(I) triflate benzene complex) were added via syringe, respectively. Finally, the disilane $(0.61 \mathrm{mmol})$ in a strongly coordinating solvent $(0.5 \mathrm{~mL})$ was added via syringe. The reaction was allowed to stir, heated to $100{ }^{\circ} \mathrm{C}$ in an oil bath under nitrogen, for 60 hours, then was allowed to cool to room temperature. Water (2-3 drops) and $p$ toluenesulfonic acid monohydrate (spatula tip) were added, and the reaction stirred for 30 minutes. The reaction mixture was partitioned between water $(5 \mathrm{~mL})$ and diethyl ether $(5 \mathrm{~mL})$, separated, and the aqueous layer was extracted with ether $(2 \times 5 \mathrm{~mL})$. The combined organics were washed twice with water and once with brine, dried over anhydrous sodium sulfate, filtered, and concentrated in vасио. The resulting mixture was purified by flash chromatography on silica gel using the noted elution solvent.

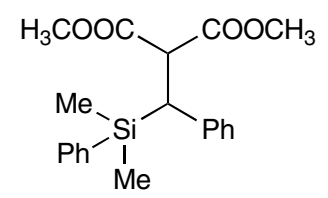

Dimethyl 2-((dimethylphenylsilyl)(phenyl)methyl)malonate (3a): Purified with $10 \%$ EtOAc/hexanes, yielding varying amounts of $3 \mathrm{a}$ as a colorless oil. $\mathrm{R}_{f}=0.40$ (15\% EtOAc/hexanes); IR (film) 3025, 2953, 1736, 1598, 1493, 1431, 1250, 1163, 838, $701 \mathrm{~cm}^{-1} ;{ }^{1} \mathrm{H}$ NMR (400 MHz, $\mathrm{CDCl}_{3}$ ) $\delta 7.41$ (m, 2H), 7.36 $(\mathrm{m}, 3 \mathrm{H}), 7.18(\mathrm{t}, J=7 \mathrm{~Hz}, 2 \mathrm{H}), 7.09(\mathrm{t}, J=7 \mathrm{~Hz}, 1 \mathrm{H}), 6.94(\mathrm{~d}, J=7 \mathrm{~Hz}, 2 \mathrm{H}), 3.95$ (d, J = $12 \mathrm{~Hz}$, $1 \mathrm{H}), 3.39(\mathrm{~s}, 3 \mathrm{H}), 3.38(\mathrm{~s}, 3 \mathrm{H}), 3.22(\mathrm{~d}, J=12 \mathrm{~Hz}, 1 \mathrm{H}), 0.16(\mathrm{~s}, 3 \mathrm{H}), 0.13(\mathrm{~s}, 3 \mathrm{H}) ;{ }^{13} \mathrm{C}$ NMR $(125$ $\left.\mathrm{MHz} \mathrm{CDCl}_{3}\right) \delta 169.2,169.1,140.2,136.5,134.6,129.5,128.5,128.3,127.8,125.7,54.2,52.6$, 52.5, 36.5, -2.6, -4.5. LRMS (electrospray): Mass calcd for $\mathrm{C}_{20} \mathrm{H}_{24} \mathrm{NaO}_{4} \mathrm{Si}[\mathrm{M}+\mathrm{Na}]^{+}, 379.13$. Found 379.

$\mathrm{H}_{3} \mathrm{COOC} \mathrm{COOCH}_{3}$ Dimethyl 2-((dimethylvinylsilyl)(phenyl)methyl)malonate (3b): Purified with $10 \%$ EtOAc/hexanes, yielding $50 \mathrm{mg}(35 \%)$ of $\mathbf{3 b}$ as a colorless oil; $\mathrm{R}_{f}$ $=0.45$ (15\% EtOAc/hexanes); IR (film) 2951, 1759, 1735, 1433, $1249 \mathrm{~cm}^{-1}$;

${ }^{1} \mathrm{H} \mathrm{NMR}\left(500 \mathrm{MHz}, \mathrm{CDCl}_{3}\right) \delta 7.23(\mathrm{t}, J=8 \mathrm{~Hz}, 2 \mathrm{H}), 7.12(\mathrm{t}, J=8 \mathrm{~Hz}, 1 \mathrm{H}), 7.08(\mathrm{~d}, J=8 \mathrm{~Hz}$, 2H), $6.02(\mathrm{~m}, 2 \mathrm{H}), 5.65(\mathrm{dd}, J=6,18 \mathrm{~Hz}, 1 \mathrm{H}), 3.99$ (d, $J=12 \mathrm{~Hz}, 1 \mathrm{H}), 3.75(\mathrm{~s}, 3 \mathrm{H}), 3.45$ (s, $3 \mathrm{H}), 3.06(\mathrm{~d}, J=12 \mathrm{~Hz}, 1 \mathrm{H}), 0.01(\mathrm{~s}, 6 \mathrm{H}) ;{ }^{13} \mathrm{C} \mathrm{NMR}\left(125 \mathrm{MHz}, \mathrm{CDCl}_{3}\right) \delta 169.4,169.3,140.4$, 136.7, 133.4, 128.4, 128.3, 125.7, 54.2, 52.8, 52.5, 36.3, -3.3, -4.5. LRMS (electrospray): Mass calcd for $\mathrm{C}_{16} \mathrm{H}_{18} \mathrm{NaO}_{4} \mathrm{Si}[\mathrm{M}+\mathrm{Na}]^{+}, 329.12$. Found 329 . 


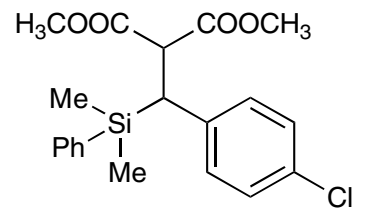

Dimethyl 2-((4-chlorophenyl)(dimethylphenylsilyl)methyl)malonate

(4): Purified with $10 \%$ EtOAc/hexanes, yielding $170 \mathrm{mg}(87 \%)$ of 4 as a colorless oil; $\mathrm{R}_{f}=0.42$ (15\% EtOAc/hexanes); IR (film) 3069, 2954, 2901, 1738, 1491, 1433, 1250, 1014, $845 \mathrm{~cm}^{-1} ;{ }^{1} \mathrm{H}$ NMR (400 MHz, $\left.\mathrm{CDCl}_{3}\right) \delta 7.36$ (m, 5H), 7.14 $(\mathrm{d}, J=8 \mathrm{~Hz}, 2 \mathrm{H}), 6.85(\mathrm{~d}, J=8 \mathrm{~Hz}, 2 \mathrm{H}), 3.89$ (d, $J=12 \mathrm{~Hz}, 1 \mathrm{H}), 3.42$ (s, 6H), 3.19 (d, $J=12$ $\mathrm{Hz}, 1 \mathrm{H}), 0.25$ (s, 3H), 0.18 (s, 3H); ${ }^{13} \mathrm{C} \mathrm{NMR}\left(125 \mathrm{MHz} \mathrm{CDCl}_{3}\right) \delta 168.9,168.8,138.8,135.9$, 134.5, 131.3, 129.7, 128.4, 127.9, 54.0, 52.8, 52.7, 36.1, -2.8, -4.4. LRMS (electrospray): Mass calcd for $\mathrm{C}_{20} \mathrm{H}_{23} \mathrm{ClNaO}_{4} \mathrm{Si}[\mathrm{M}+\mathrm{Na}]^{+}$, 413.10. Found 413 .

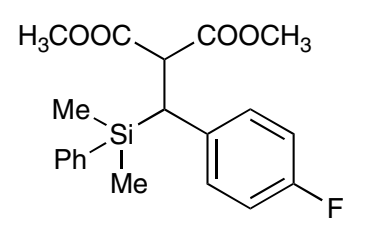

Dimethyl 2-((4-fluorophenyl)(dimethylphenylsilyl)methyl)malonate (5): Purified with 10\% EtOAc/hexanes, yielding $100 \mathrm{mg}(53 \%)$ of 5 as a colorless oil; $\mathrm{R}_{f}=0.34$ (15\% EtOAc/hexanes); IR (film) 3071, 2955, 1731, 1509, 1435, 1223, $845 \mathrm{~cm}^{-1} ;{ }^{1} \mathrm{H} \mathrm{NMR}\left(400 \mathrm{MHz} \mathrm{CDCl}_{3}\right) \delta 7.36(\mathrm{~m}, 5 \mathrm{H})$, $6.87(\mathrm{~d}, J=7 \mathrm{~Hz}, 4 \mathrm{H}), 3.88(\mathrm{~d}, J=12 \mathrm{~Hz}, 1 \mathrm{H}), 3.43$ (s, 3H), $3.41(\mathrm{~s}, 3 \mathrm{H}), 3.19$ (d, $J=12 \mathrm{~Hz}$, $1 \mathrm{H}), 0.25(\mathrm{~s}, 3 \mathrm{H}), 0.18(\mathrm{~s}, 3 \mathrm{H}) ;{ }^{13} \mathrm{C} \mathrm{NMR}\left(100 \mathrm{MHz}, \mathrm{CDCl}_{3}\right) \delta 169.0,168.9,161.1(\mathrm{~d}, J=243$ Hz), 136.1, 135.7, 134.5, 129.8 (d, $J=7 \mathrm{~Hz}), 129.6,127.9,115.2$ (d, $J=21 \mathrm{~Hz}), 54.2,52.7,52.6$, 35.8, -2.7, -4.3. LRMS (electrospray): Mass calcd for $\mathrm{C}_{20} \mathrm{H}_{23} \mathrm{FNaO}_{4} \mathrm{Si}[\mathrm{M}+\mathrm{Na}]^{+}, 397.12$. Found 397.

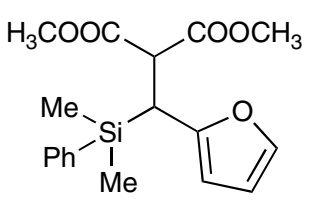

Dimethyl 2-((furan-2-yl)(dimethylphenylsilyl)methyl)malonate (7): Purified with $10 \%$ EtOAc/hexanes, yielding $138 \mathrm{mg}(80 \%)$ of 7 as a colorless oil. $\mathrm{R}_{f}=0.37$ (15\% EtOAc/hexanes); IR (film) 3001, 2954, 2903, 2845, 1739, 1584, 1503, 1434, 1260, 1159, 1012, 839, $735 \mathrm{~cm}^{-1} ;{ }^{1} \mathrm{H}$ NMR $\left(500 \mathrm{MHz}, \mathrm{CDCl}_{3}\right) \delta$ $7.40(\mathrm{~m}, 2 \mathrm{H}), 7.29(\mathrm{~m}, 3 \mathrm{H}), 7.20(\mathrm{~d}, J=2 \mathrm{~Hz}, 1 \mathrm{H}), 6.17(\mathrm{dd}, J=2,2 \mathrm{~Hz}, 1 \mathrm{H}), 5.82(\mathrm{~d}, J=2 \mathrm{~Hz}$, $1 \mathrm{H}), 3.73(\mathrm{~d}, J=11 \mathrm{~Hz}, 1 \mathrm{H}), 3.46(\mathrm{~s}, 3 \mathrm{H}), 3.30(\mathrm{~s}, 3 \mathrm{H}), 3.28(\mathrm{~d}, J=12 \mathrm{~Hz}, 1 \mathrm{H}), 0.26(\mathrm{~s}, 3 \mathrm{H})$, $0.19(\mathrm{~s}, 3 \mathrm{H}) ;{ }^{13} \mathrm{C} \mathrm{NMR}\left(125 \mathrm{MHz}, \mathrm{CDCl}_{3}\right) \delta 169.3,168.7,154.2,141.1,136.5,134.4,129.5$, 127.8, 110.6, 106.0, 52.8, 52.7, 52.5, 29.7, -2.8, -4.2. LRMS (electrospray): Mass calcd for $\mathrm{C}_{18} \mathrm{H}_{22} \mathrm{NaO}_{5} \mathrm{Si}[\mathrm{M}+\mathrm{Na}]^{+}, 369.11$. Found 369 . 


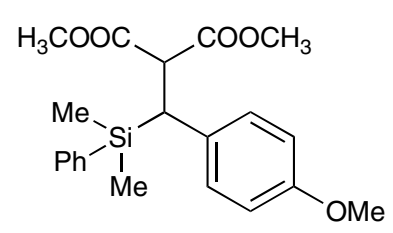

\section{Dimethyl 2-((4-methoxyphenyl)(dimethylphenylsilyl)methyl)}

malonate (8): Purified with $10 \%$ EtOAc/hexanes, yielding $130 \mathrm{mg}$ (67\%) of $\mathbf{8}$ as a colorless oil. $\mathrm{R}_{f}=0.29$ (15\% EtOAc/hexanes); IR (film) 3002, 2954, 2904, 2838, 1758, 1737, 1511, 1433, 1251, 1033, $842 \mathrm{~cm}^{-1}$;

${ }^{1} \mathrm{H} \mathrm{NMR}\left(400 \mathrm{MHz}, \mathrm{CDCl}_{3}\right) \delta 7.37(\mathrm{~m}, 2 \mathrm{H}), 7.30(\mathrm{~m}, 3 \mathrm{H}), 6.83(\mathrm{~d}, J=8 \mathrm{~Hz}, 2 \mathrm{H}), 6.69$ (d, $J=8$ $\mathrm{Hz}, 2 \mathrm{H}), 3.85$ (d, $J=12 \mathrm{~Hz}, 1 \mathrm{H}), 3.72(\mathrm{~s}, 3 \mathrm{H}), 3.37$ (s, 3H) 3.34 (s, 3H), $3.11(\mathrm{~d}, J=12 \mathrm{~Hz}, 1 \mathrm{H})$, $0.22(\mathrm{~s}, 3 \mathrm{H}), 0.12(\mathrm{~s}, 3 \mathrm{H}) ;{ }^{13} \mathrm{C}$ NMR $\left(100 \mathrm{MHz}, \mathrm{CDCl}_{3}\right) \delta 169.2,169.0,157.5,136.5,134.5$, 131.8, 129.4, 127.7, 113.7, 55.3, 54.3, 52.6, 52.5, 35.5, -2.6, -4.4. LRMS (electrospray): Mass calcd for $\mathrm{C}_{21} \mathrm{H}_{26} \mathrm{NaO}_{5} \mathrm{Si}[\mathrm{M}+\mathrm{Na}]^{+}$, 409.14. Found 409 .

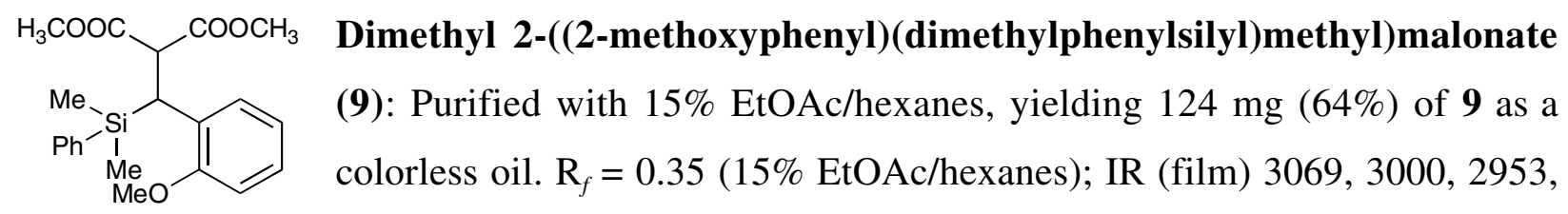
2838, 1738, 1585, 1492, 1435, $1246 \mathrm{~cm}^{-1} ;{ }^{1} \mathrm{H}$ NMR (400 MHz, $\left.\mathrm{CDCl}_{3}\right) \delta 7.45(\mathrm{~m}, 2 \mathrm{H}), 7.33(\mathrm{~m}$, $3 \mathrm{H}), 7.11(\mathrm{t}, J=8 \mathrm{~Hz}, 1 \mathrm{H}), 6.94(\mathrm{~d}, J=7 \mathrm{~Hz}, 1 \mathrm{H}), 6.84(\mathrm{t}, J=7 \mathrm{~Hz}, 1 \mathrm{H}), 6.76(\mathrm{~d}, J=8 \mathrm{~Hz}, 1 \mathrm{H})$, $4.13(\mathrm{~d}, J=12 \mathrm{~Hz}, 1 \mathrm{H}), 3.77(\mathrm{~s}, 3 \mathrm{H}), 3.60,(\mathrm{bm}, 1 \mathrm{H}), 3.41$ (s, 3H), 3.39 (s, 3H), $0.24(\mathrm{~s}, 3 \mathrm{H})$, $0.20(\mathrm{~s}, 3 \mathrm{H}) ;{ }^{13} \mathrm{C}$ NMR $\left(100 \mathrm{MHz}, \mathrm{CDCl}_{3}\right) \delta 169.6,169.5,157.0,137.6,134.5,129.1,127.6$, 126.8, 120.5, 110.4, 55.1, 53.4, 52.5, 52.3, -2.5, -4.0. LRMS (electrospray): Mass calcd for $\mathrm{C}_{21} \mathrm{H}_{26} \mathrm{NaO}_{5} \mathrm{Si}[\mathrm{M}+\mathrm{Na}]^{+}$, 409.14. Found 409 .

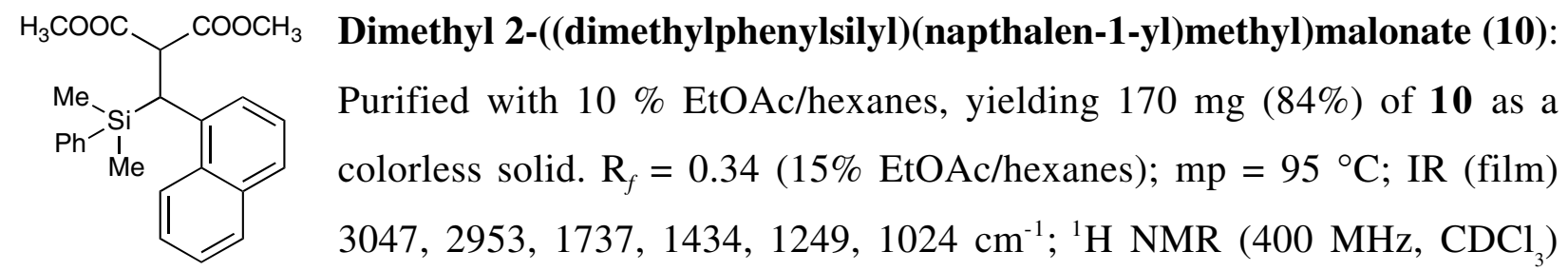

$\delta 8.24(\mathrm{~d}, J=8 \mathrm{~Hz}, 1 \mathrm{H}), 7.80(\mathrm{~d}, J=8 \mathrm{~Hz}, 1 \mathrm{H}), 7.62(\mathrm{~d}, J=8 \mathrm{~Hz}, 1 \mathrm{H}), 7.5-7.2(\mathrm{~m}, 8 \mathrm{H}), 7.01(\mathrm{~d}$, $J=7 \mathrm{~Hz}, 1 \mathrm{H}), 4.21(\mathrm{~d}, J=13 \mathrm{~Hz}, 1 \mathrm{H}), 4.13(\mathrm{~d}, J=13 \mathrm{~Hz}, 1 \mathrm{H}), 3.40(\mathrm{~s}, 3 \mathrm{H}), 3.24(\mathrm{~s}, 3 \mathrm{H}), 0.17$ (s, 3H), 0.07 (s, 3H); ${ }^{13} \mathrm{C}$ NMR (100 MHz, $\mathrm{CDCl}_{3}$ ) $\delta$ 169.1, 169.0, 137.4, 136.5, 134.6, 134.1, 
132.3, 129.5, 128.9, 127.8, 126.2, 126.0, 125.7, 125.1, 124.0, 55.1, 52.7, 52.5, 29.7, -2.1, -4.5. LRMS (electrospray): Mass calcd for $\mathrm{C}_{24} \mathrm{H}_{26} \mathrm{NaO}_{4} \mathrm{Si}[\mathrm{M}+\mathrm{Na}]^{+}$, 429.15. Found 429 .

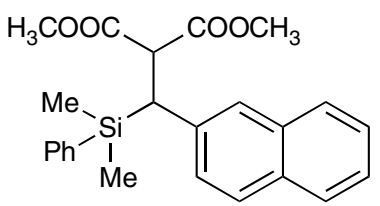

Dimethyl 2-((dimethylphenylsilyl)(napthalen-2-yl)methyl)malonate (11): Purified with 15\% EtOAC/hexanes, yielding $170 \mathrm{mg}$ (84\%) of $\mathbf{1 1}$ as a white crystalline solid. $\mathrm{R}_{f}=0.24(15 \%$ EtOAc/hexanes); $\mathrm{mp}=92$ ${ }^{\circ} \mathrm{C}$; IR (film) 3052, 2953, 2901, 1737, 1631, 1599, 1432, $1251 \mathrm{~cm}^{-1}$; ${ }^{1} \mathrm{H}$ NMR (400 MHz, $\mathrm{CDCl}_{3}$ ) $\delta 7.77(\mathrm{~d}, J=8 \mathrm{~Hz}, 1 \mathrm{H}), 7.68(\mathrm{~d}, J=8 \mathrm{~Hz}, 2 \mathrm{H}), 7.45-7.32(\mathrm{~m}, 8 \mathrm{H}), 7.13(\mathrm{~d}, J=7 \mathrm{~Hz}, 1 \mathrm{H}), 4.07$ (d, $J=12 \mathrm{~Hz}, 1 \mathrm{H}), 3.42$ (s, 3H), 3.41 (d, $J=12 \mathrm{~Hz}, 1 \mathrm{H}), 3.35$ (s, 3H), $0.28(\mathrm{~s}, 3 \mathrm{H}), 0.19$ (s, 3H); ${ }^{13} \mathrm{C}$ NMR (100 MHz, $\left.\mathrm{CDCl}_{3}\right) \delta 169.3,169.2,138.2,136.5,134.8,133.7,132.1,129.7,128.0$, $127.9,127.8,126.4,126.23,125.5,54.4,52.8,52.7,36.8,-2.42,-4.3$. LRMS (electrospray): Mass calcd for $\mathrm{C}_{24} \mathrm{H}_{26} \mathrm{NaO}_{4} \mathrm{Si}[\mathrm{M}+\mathrm{Na}]^{+}, 429.15$. Found 429 .

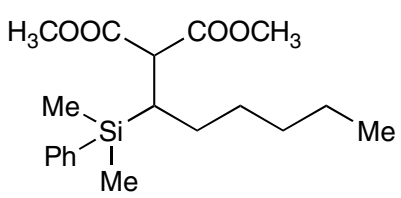

Dimethyl 2-(1-(dimethylphenylsilyl)hexyl)malonate (12): Purified with $8 \%$ EtOAc/hexanes, yielding $83 \mathrm{mg}(60 \%$ based on $80 \%$ pure starting material by $\left.{ }^{1} \mathrm{H} N \mathrm{NMR}\right)^{5}$ of $\mathbf{1 2}$ as a colorless oil. $\mathrm{R} f=0.53(15 \%$

EtOAc/hexanes); IR (film) 3069, 2954, 2929, 2858, 1373, 1435, 1250, 1152, $819 \mathrm{~cm}^{-1}$; ${ }^{1} \mathrm{H}$ NMR $\left(400 \mathrm{MHz}, \mathrm{CDCl}_{3}\right) \delta 7.52(\mathrm{~m}, 2 \mathrm{H}), 7.34(\mathrm{~m}, 3 \mathrm{H}), 3.62(\mathrm{~s}, 3 \mathrm{H}), 3.60(\mathrm{~s}, 3 \mathrm{H}), 3.52(\mathrm{~d}, J=7 \mathrm{~Hz}$, 1H), 1.6-1.1 (m, 8H), $0.81(\mathrm{t}, J=7 \mathrm{~Hz}, 3 \mathrm{H}), 0.34(\mathrm{~s}, 3 \mathrm{H}), 0.31(\mathrm{~s}, 3 \mathrm{H}) ;{ }^{13} \mathrm{C}$ NMR $(100 \mathrm{MHz}$, $\left.\mathrm{CDCl}_{3}\right) \delta 170.6,170.4,138.7,134.3,129.2,127.9,52.9,52.4,52.3,32.0,29.1,28.7,26.5,22.6$, 14.2, -2.9, -3.2. LRMS (electrospray): Mass calcd for $\mathrm{C}_{19} \mathrm{H}_{30} \mathrm{NaO}_{4} \mathrm{Si}[\mathrm{M}+\mathrm{Na}]^{+}, 373.13$. Found 373.

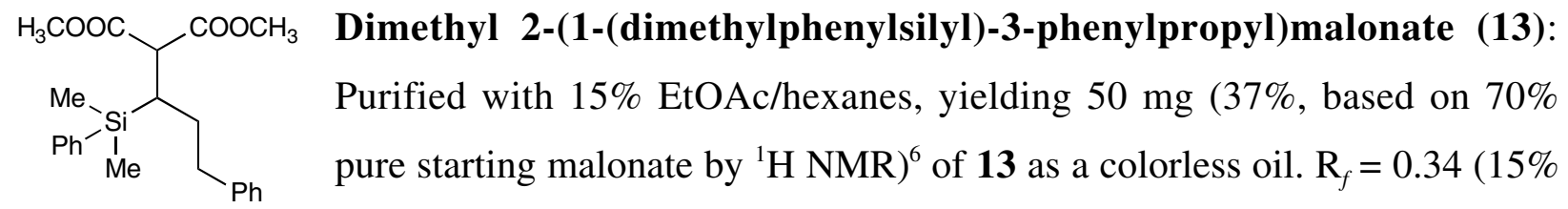

(5) All attempts to isolate dimethyl 2-hexylidenemalonate with greater that $80 \%$ purity (via distillation and/or silica gel chromatography) were unsuccessful. Currently, methods to obtain this malonate in greater purity are under investigation.

(6) Similarly, attempts to isolate dimethyl 2-(3-phenylpropylidene)malonate (via distillation and/or silica gel chromatography) with greater than $70 \%$ purity were unsuccessful. 
EtOAc/hexanes); IR (film) 3025, 2953, 2861, 1736, 1434, 1250, 1155, $1111 \mathrm{~cm}^{-1} ;{ }^{1} \mathrm{H}$ NMR (400 $\left.\mathrm{MHz}, \mathrm{CDCl}_{3}\right) \delta 7.53(\mathrm{~m}, 3 \mathrm{H}), 7.36(\mathrm{~m}, 2 \mathrm{H}), 7.23(\mathrm{t}, J=7 \mathrm{~Hz}, 2 \mathrm{H}), 7.15(\mathrm{t}, J=7 \mathrm{~Hz}, 1 \mathrm{H}), 7.01$ $(\mathrm{d}, J=7 \mathrm{~Hz}, 2 \mathrm{H}), 3.65(\mathrm{~s}, 3 \mathrm{H}), 3.63(\mathrm{~s}, 3 \mathrm{H}), 3.60(\mathrm{~d}, J=6 \mathrm{~Hz}, 1 \mathrm{H}), 2.58(\mathrm{~m}, 1 \mathrm{H}), 2.46(\mathrm{~m}, 1 \mathrm{H})$, $1.81(\mathrm{~m}, 2 \mathrm{H}), 1.72(\mathrm{~m}, 1 \mathrm{H}), 0.38(\mathrm{~s}, 3 \mathrm{H}), 0.34(\mathrm{~s}, 3 \mathrm{H}) ;{ }^{13} \mathrm{C} \mathrm{NMR}\left(125 \mathrm{MHz}, \mathrm{CDCl}_{3}\right) \delta$ 170.6, $170.2,142.3,138.4,134.3,129.3,128.5,128.0,126.0,52.8,52.5,35.9,31.1,26.3,-2.9,-3.5$. LRMS (electrospray): Mass calcd for $\mathrm{C}_{22} \mathrm{H}_{28} \mathrm{NaO}_{4} \mathrm{Si}[\mathrm{M}+\mathrm{Na}]^{+}$, 407.17. Found 407.

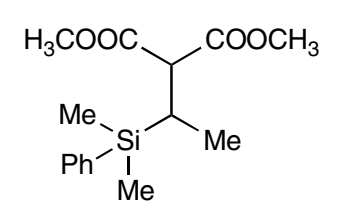

Dimethyl 2-(1-(dimethylphenylsilyl)ethyl)malonate (14): Purified with $10 \%$ EtOAc/hexanes, yielding $60 \mathrm{mg}(40 \%)^{7}$ of $\mathbf{1 4}$ as a colorless oil. $\mathrm{R}_{f}=$ 0.33 (15\% EtOAc/hexanes); IR (film) 3070, 3000, 2954, 1737, 1435, 1251, $1016 \mathrm{~cm}^{-1} ;{ }^{1} \mathrm{H}$ NMR (400 MHz, $\left.\mathrm{CDCl}_{3}\right) \delta 7.50(\mathrm{~m}, 2 \mathrm{H}), 7.35$ (m, 3H), $3.65(\mathrm{~s}, 3 \mathrm{H}), 3.54(\mathrm{~s}, 3 \mathrm{H})$, $3.37(\mathrm{~d}, J=8 \mathrm{~Hz}, 1 \mathrm{H}), 1.81(\mathrm{dt}, J=8,7 \mathrm{~Hz}, 1 \mathrm{H}), 1.03(\mathrm{~d}, J=7 \mathrm{~Hz}, 3 \mathrm{H}), 0.31(\mathrm{~s}, 6 \mathrm{H}) ;{ }^{13} \mathrm{C} \mathrm{NMR}$ $\left(100 \mathrm{MHz}, \mathrm{CDCl}_{3}\right) \delta 170.1,137.5,134.3,129.4,128.0,54.0,52.5,52.3,10.65,13.0,-4.1,-4.3$. LRMS (electrospray): Mass calcd for $\mathrm{C}_{15} \mathrm{H}_{22} \mathrm{NaO}_{4} \mathrm{Si}[\mathrm{M}+\mathrm{Na}]^{+}$, 317.12. Found 317.

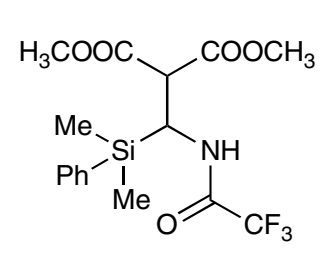

\section{Dimethyl 2-((2,2,2-trifluoroacetamido)(dimethylphenylsilyl)}

methyl)malonate (15): Purified with 15\% EtOAc/ hexanes, yielding $111 \mathrm{mg}$ (57\%) of $\mathbf{1 5}$ as a colorless oil. $\mathrm{R}_{f}=0.23$ (15\% EtOAc/hexanes); IR (film) 3073, 3012, 2957, 1724, 1529, 1438, 1213, $1162 \mathrm{~cm}^{-1}$; ${ }^{1} \mathrm{H}$ NMR $(500 \mathrm{MHz}$, $\left.\mathrm{CDCl}_{3}\right) \delta 7.61(\mathrm{~d}, J=10 \mathrm{~Hz}, 1 \mathrm{H}), 7.52(\mathrm{~m}, 2 \mathrm{H}), 7.42(\mathrm{~m}, 3 \mathrm{H}), 4.42(\mathrm{dd}, J=10,3 \mathrm{~Hz}, 1 \mathrm{H}), 3.68$ (s, 3H), $3.61(\mathrm{~s}, 3 \mathrm{H}), 3.52$ (d, $J=3 \mathrm{~Hz}, 1 \mathrm{H}), 0.45$ (s, 3H), 0.43 (s, 3H); ${ }^{13} \mathrm{C}$ NMR $(125 \mathrm{MHz}$, $\left.\mathrm{CDCl}_{3}\right) \delta 170.0,168.4,157.0(\mathrm{q}, J=37 \mathrm{~Hz}), 134.2,134.1,130.5,128.45,116.2(\mathrm{q}, J=288 \mathrm{~Hz})$, 53.3, 53.0, 50.9, 40.6, -3.9, -4.8. LRMS (electrospray): Mass calcd for $\mathrm{C}_{16} \mathrm{H}_{20} \mathrm{~F}_{3} \mathrm{NNaO}_{5} \mathrm{Si}$ $[\mathrm{M}+\mathrm{Na}]^{+}, 414.10$. Found 414 .

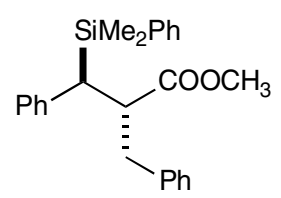

(2RS,3RS)-Methyl 2-benzyl-3-(dimethylphenylsilyl)-3-phenylpropanoate (17). Lithium chloride (24 mg, $0.57 \mathrm{mmol})$ was added to a stirring solution of

(7) Dimethyl 2-ethylidenemalonate appeared to decompose slightly upon distillation at temperature lower than 100 ${ }^{\circ} \mathrm{C}$. Thus, decomposition of the starting material in situ could be the reason for a low yield. 
3a $(50 \mathrm{mg}, 0.14 \mathrm{mmol})$ and water (1 drop) in DMSO $(2 \mathrm{~mL})$. The reaction was heated in an oil bath to $140{ }^{\circ} \mathrm{C}$ for 3.5 hours. It was diluted with $100 \mathrm{~mL}$ of water, and was extracted with EtOAc (3x50 mL). The combined organics were washed with water and brine, dried over anhydrous sodium sulfate, filtered, and concentrated in vacuo. The residue was purified by flash chromatography over silica gel (7\% EtOAc/hexanes) to give $30 \mathrm{mg}(72 \%)$ of a colorless oil that was identical by ${ }^{1} \mathrm{H}$ NMR and TLC to previously reported methyl 3-(dimethylphenylsilyl)-3phenylpropanoate. ${ }^{8}$ To a solution of diisopropylamine $(335 \mu \mathrm{L}, 2.4 \mathrm{mmol})$ in THF $(2.5 \mathrm{~mL})$ cooled to $-78{ }^{\circ} \mathrm{C}$ was added butyllithium (1.6 M in hexanes, $\left.1.5 \mathrm{~mL}, 2.4 \mathrm{mmol}\right)$. It was allowed to warm to $0{ }^{\circ} \mathrm{C}$ and stir for 10 minutes, then was cooled to $-78^{\circ} \mathrm{C}$. To this, a solution of methyl 3-(dimethylphenylsilyl)-3-phenylpropanoate $(500 \mathrm{mg}, 1.68 \mathrm{mmol})$ in THF (5 mL) was added via cannula. It was allowed to stir for 30 minutes, and then benzyl bromide $(250 \mu \mathrm{L}, 2.1 \mathrm{mmol})$ was added via syringe. The reaction was warmed to room temperature and allowed to react for 10 hours. Saturated ammonium chloride $(15 \mathrm{~mL})$ was added, and it was extracted with EtOAc $(2 \times 30$ $\mathrm{mL}$ ). The organics were washed with brine, dried over anhydrous sodium sulfate, filtered, and concentrated in vacuo. The unpurified reaction mixture contained a single diastereomer by ${ }^{1} \mathrm{H}$ NMR (500 Mhz). Coupling constants matched data reported for similar anti diastereomers. ${ }^{9}$ The residue was purified by flash chromatography over silica gel (7\% EtOAc/hexanes) to give 560 $\mathrm{mg}(86 \%)$ of 17 as a colorless solid. $\mathrm{R}_{\mathrm{f}}=0.51\left(15 \%\right.$ EtOAc/hexanes); $\mathrm{mp}=65^{\circ} \mathrm{C}$; IR (film) 3023, 2947, 1733, 1489, $1450 \mathrm{~cm}^{-1} ;{ }^{1} \mathrm{H}$ NMR (500 MHz, $\left.\mathrm{CDCl}_{3}\right) \delta 7.5-7.1(\mathrm{~m}, 11 \mathrm{H}), 7.04(\mathrm{~d}, J=$ $7 \mathrm{~Hz}, 2 \mathrm{H}), 6.98(\mathrm{~d}, J=7 \mathrm{~Hz}, 2 \mathrm{H}), 3.18(\mathrm{~m}, 1 \mathrm{H}), 3.17$ (s, 3H), 2.75 (d, J=12 Hz, 2H), 2.59 (dd, $J$ $=12,13 \mathrm{~Hz}, 1 \mathrm{H}), 0.33$, (s, 3H), $0.13(\mathrm{~s}, 3 \mathrm{H}) ;{ }^{13} \mathrm{C} \mathrm{NMR}\left(125 \mathrm{MHz}, \mathrm{CDCl}_{3}\right) \delta 175.2,141.0,139.6$, 137.2, 134.6, 129.3, 128.9, 128.8, 128.6, 128.4, 127.7, 126.4, 125.6, 51.2, 49.6, 39.8, 39.6, -2.4, -4.6. LRMS (electrospray): Mass calcd for $\mathrm{C}_{25} \mathrm{H}_{28} \mathrm{NaO}_{2} \mathrm{Si}[\mathrm{M}+\mathrm{Na}]^{+}, 411.18$. Found 411 .

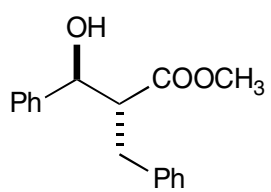

\section{(2RS,3SR)-Methyl 2-benzyl-3-hydroxy-3-phenylpropanoate (18)}

Tetrafluoroboric acid diethyl ether complex $(0.1 \mathrm{~mL})$ was added to a stirring solution of 17 (206 mg, $0.5 \mathrm{mmol})$ in dichloromethane $(1 \mathrm{~mL})$ at room

(8) Fleming, I.; Newton, T. W. J. Chem. Soc., Perkin Trans. 1, 1984, 1805-1808.

(9) Fleming, I.; Waterson, D. J. Chem. Soc., Perkin Trans. 1, 1984, 1809-1815. 
temperature. The reaction was allowed to stir for two hours. It was quenched with water (10 $\mathrm{mL})$, and the mixture was extracted with EtOAc $(2 \times 15 \mathrm{~mL})$. The combined organics were washed with brine, dried over anhydrous sodium sulfate, filtered, and concentrated in vacuo. The residue was dissolved in diethyl ether $(1 \mathrm{~mL})$ and cooled to $0{ }^{\circ} \mathrm{C} . \mathrm{m}$-Chloroperbenzoic acid (350 $\mathrm{mg}, 2.0 \mathrm{mmol})$ was added, followed by dropwise addition of triethylamine $(84 \mu \mathrm{L}, 0.60 \mathrm{mmol})$ in ether $(0.5 \mathrm{~mL})$. The mixture was warmed to room temperature, and stirred for 2.25 hours. The reaction was quenched by the addition of saturated sodium sulfite $(7 \mathrm{~mL})$. The organic layer was separated, washed with saturated sodium sulfite and $0.5 \%$ aqueous hydrochloric acid, and concentrated in vacuo. The residue was taken up in methanol $(5 \mathrm{~mL})$, and concentrated hydrochloric acid (2-3 drops) was added. After 15 minutes, it was concentrated again, taken up in ether, washed with saturated sodium bicarbonate and saturated sodium chloride, dried over anhydrous sodium sulfate, filtered, and concentrated in vacuo to give $120 \mathrm{mg}$ (89\%) of $\mathbf{1 8}$ as a white solid. The product was $\geq 95 \%$ pure by ${ }^{1} \mathrm{H}$ and ${ }^{13} \mathrm{C}$ NMR and identical to spectra previously reported for known compound $\mathbf{1 8} .^{10}$

(10) Ranu, B. C.; Saha, M.; Bhar, S. Synth. Commun. 1997, 27, 3065-3078. 


\section{Selected ${ }^{1}$ H NMR Spectra:}
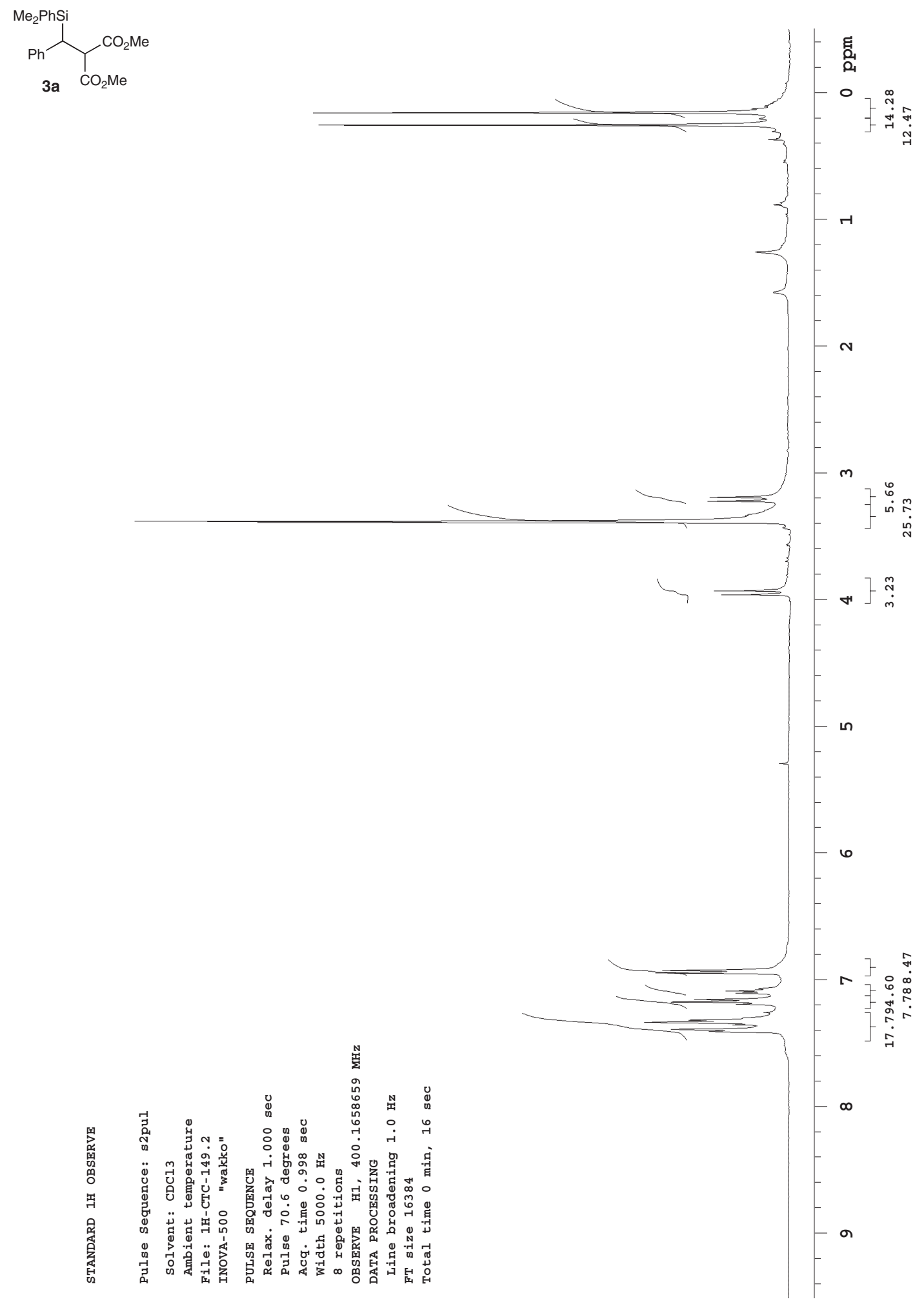
<smiles>C=C[Si](C)(C)C(c1ccccc1)C(C(C)=O)C(C)=O</smiles><smiles>COCC(C(C)=O)C(C)OC</smiles>

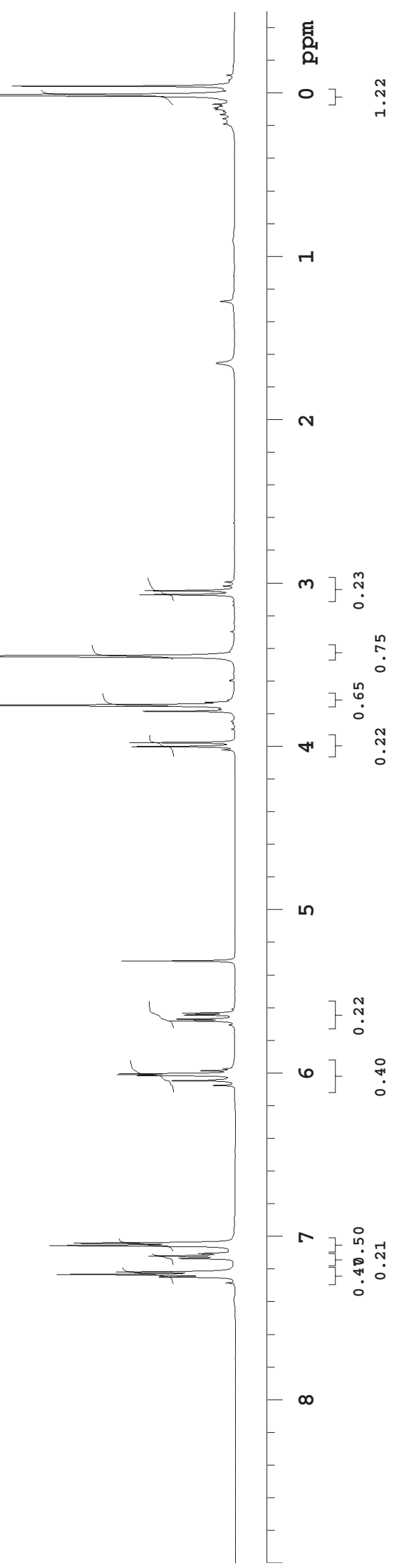




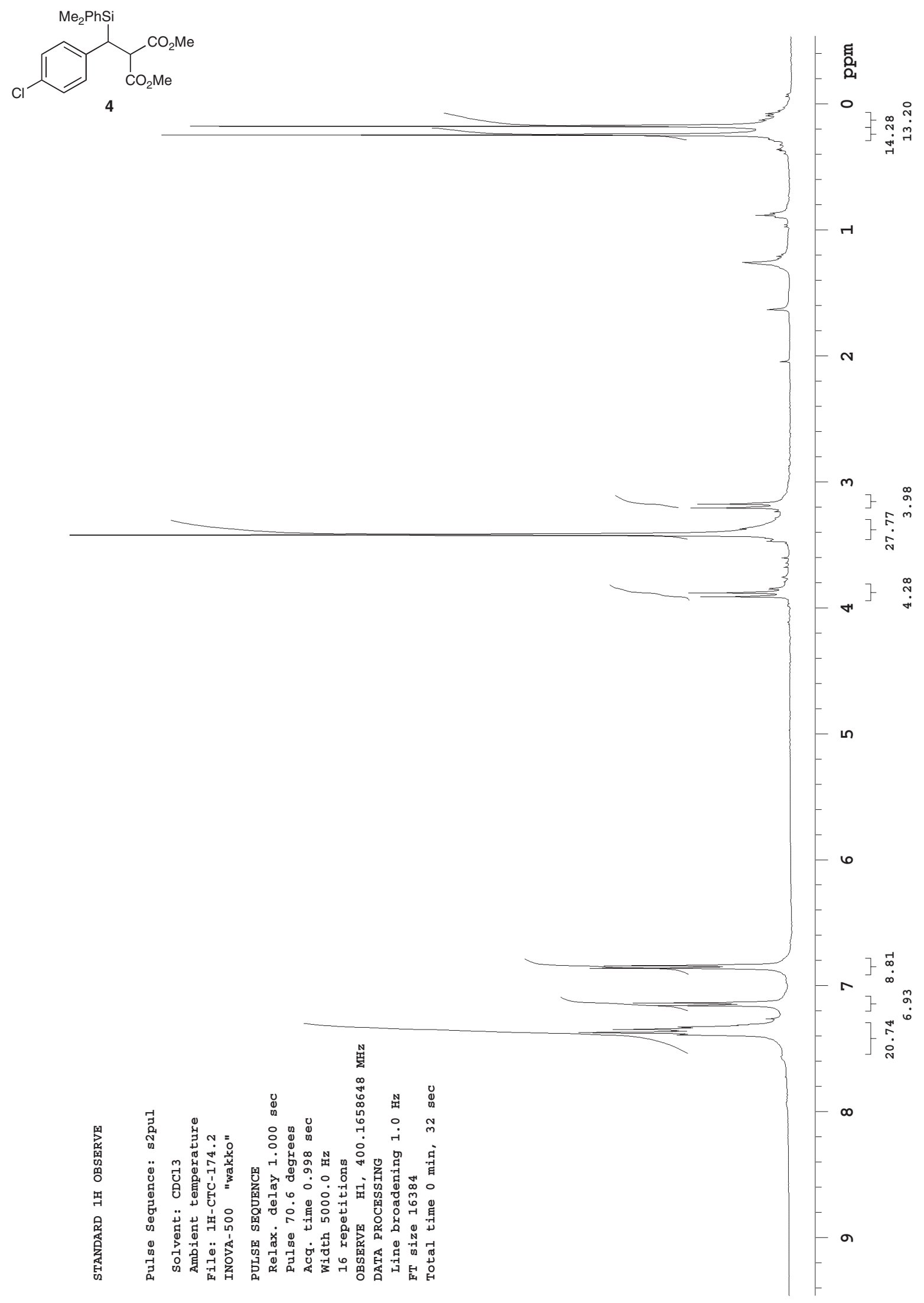




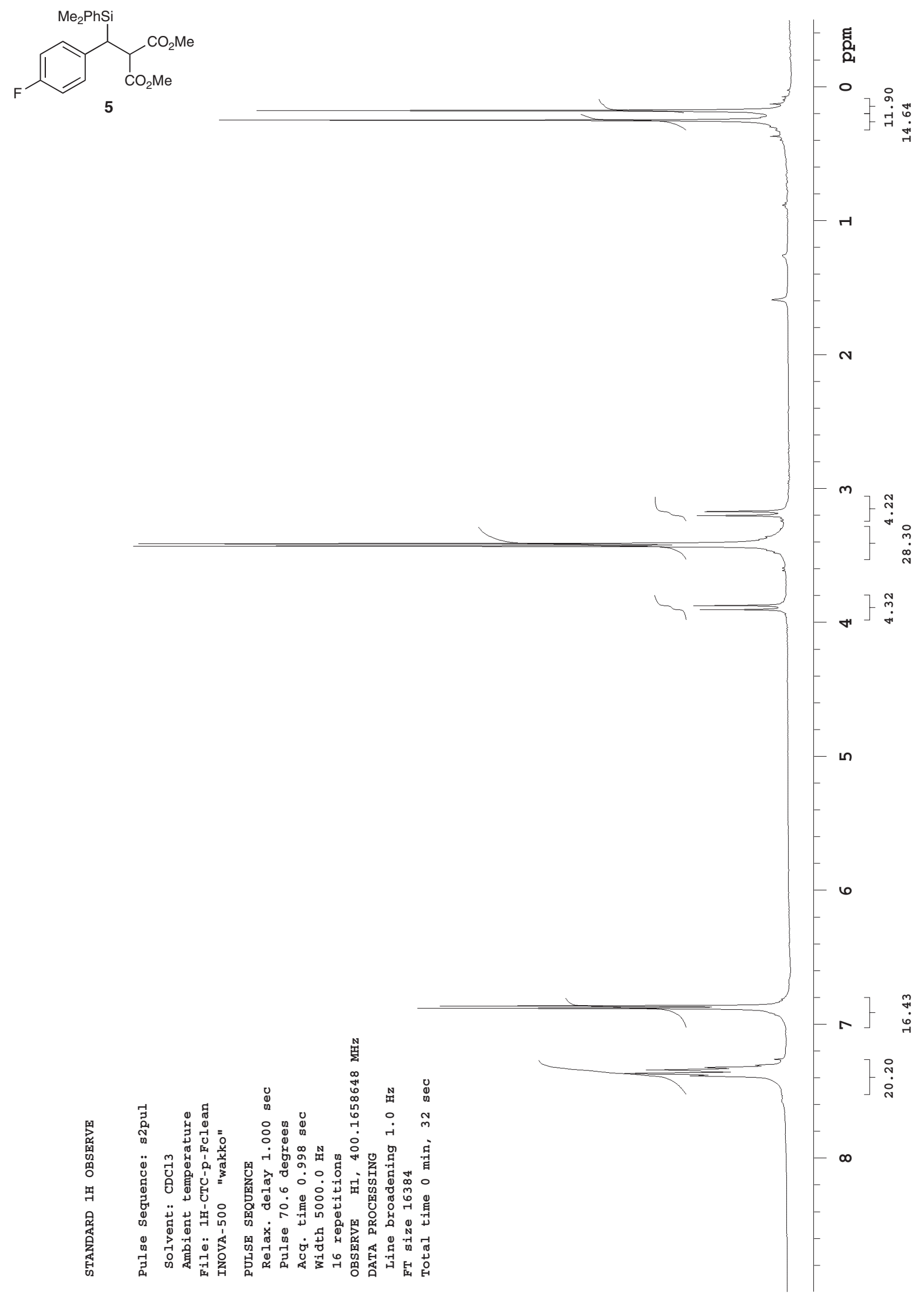



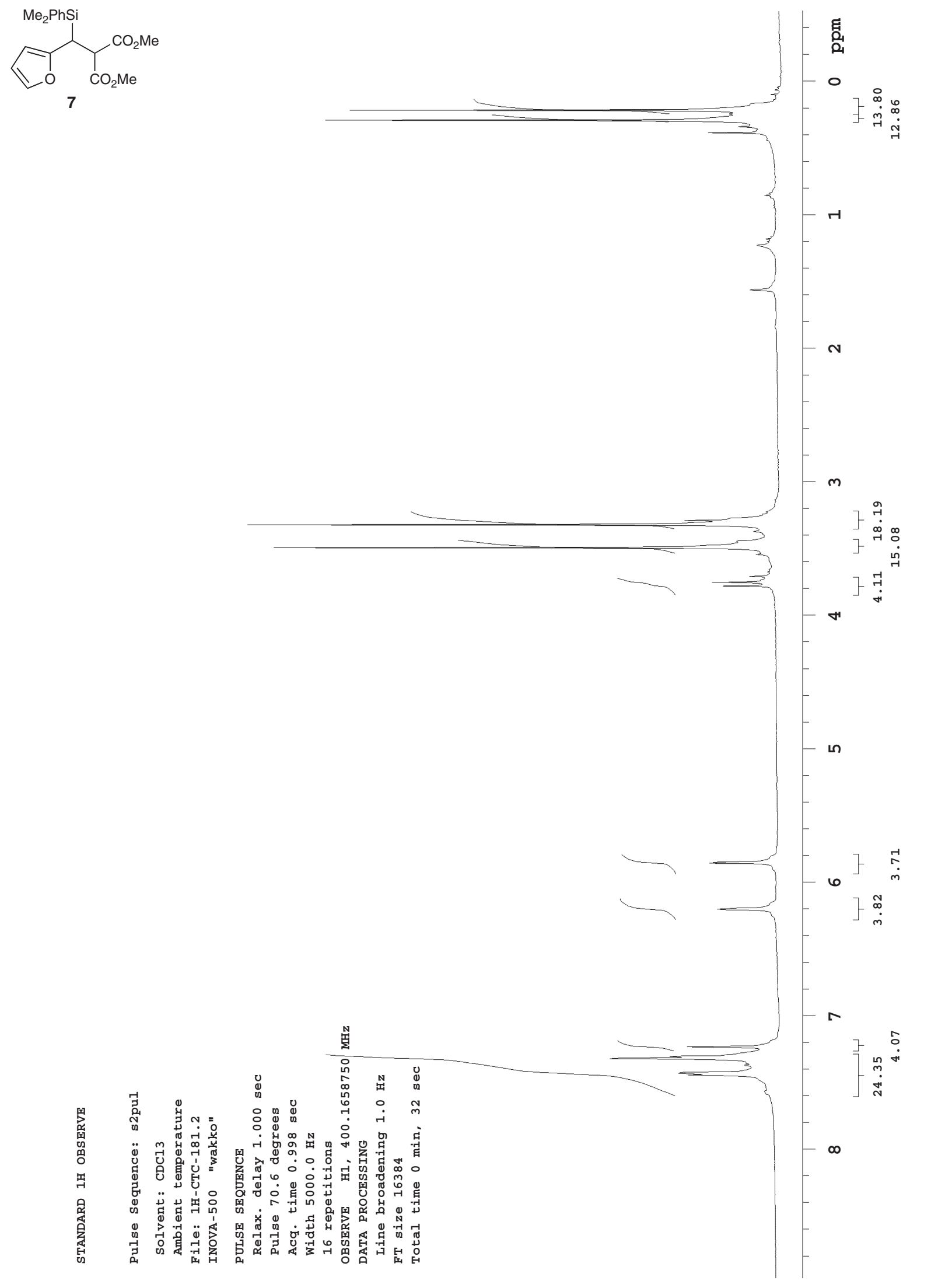


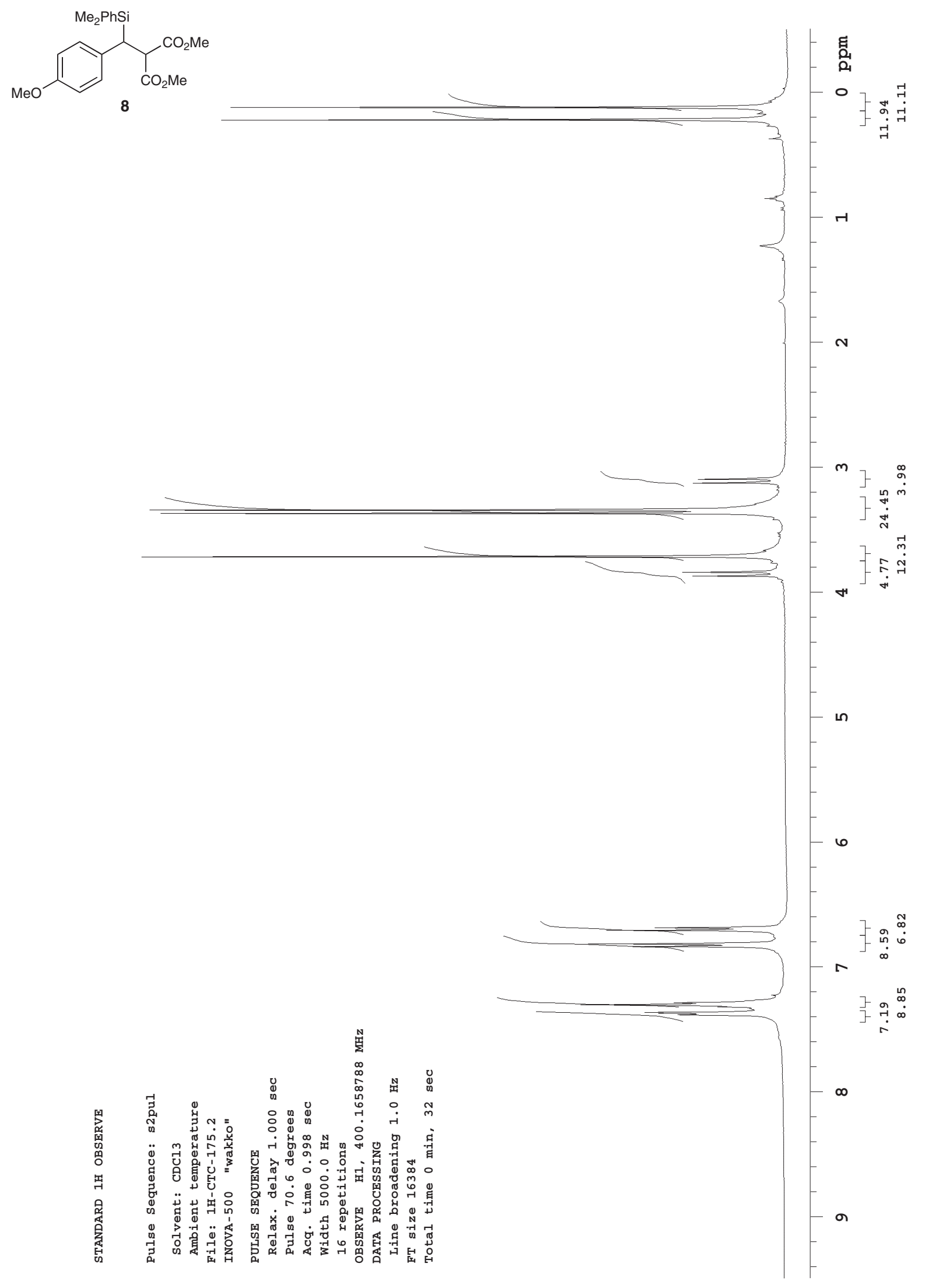



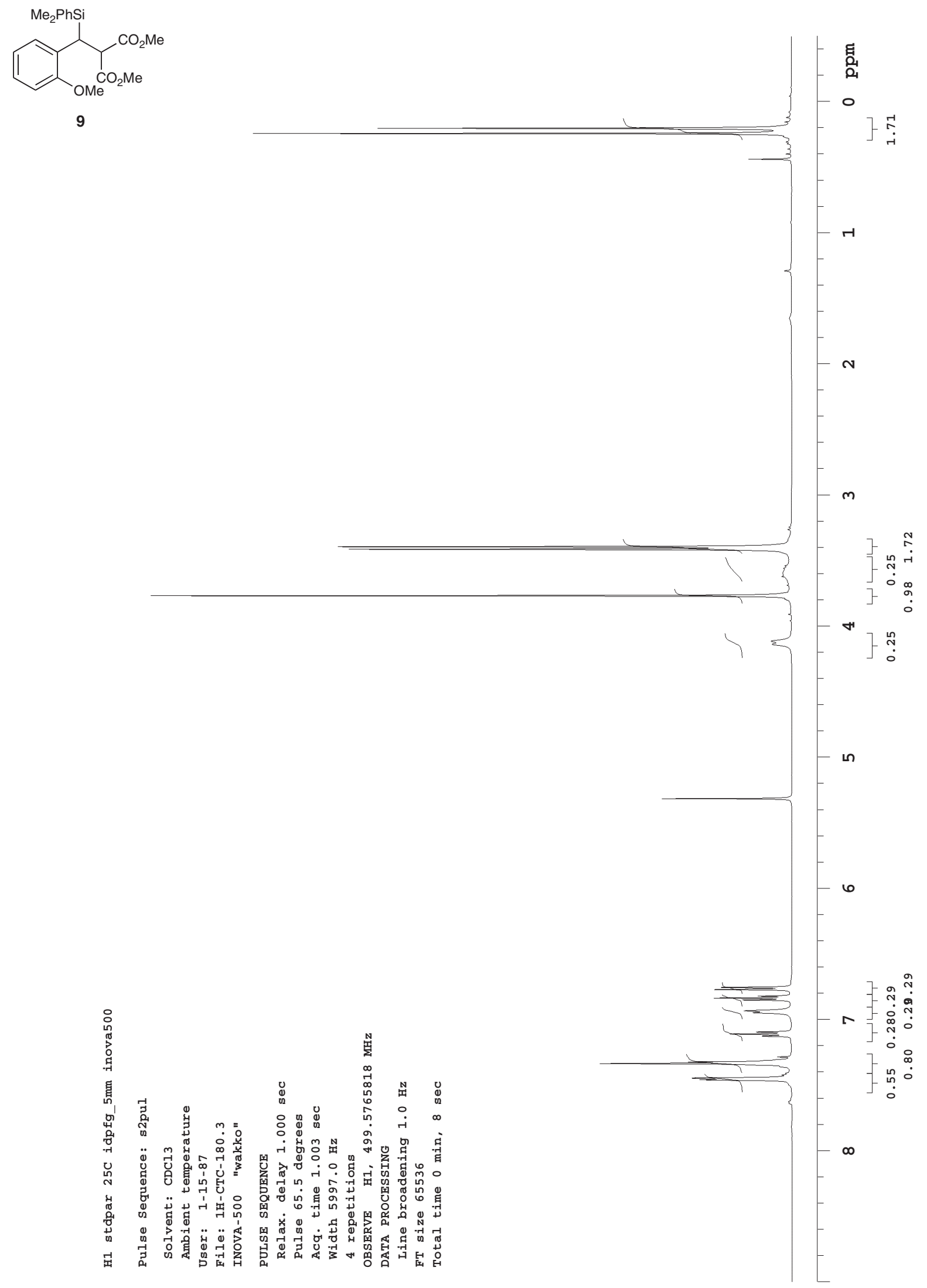

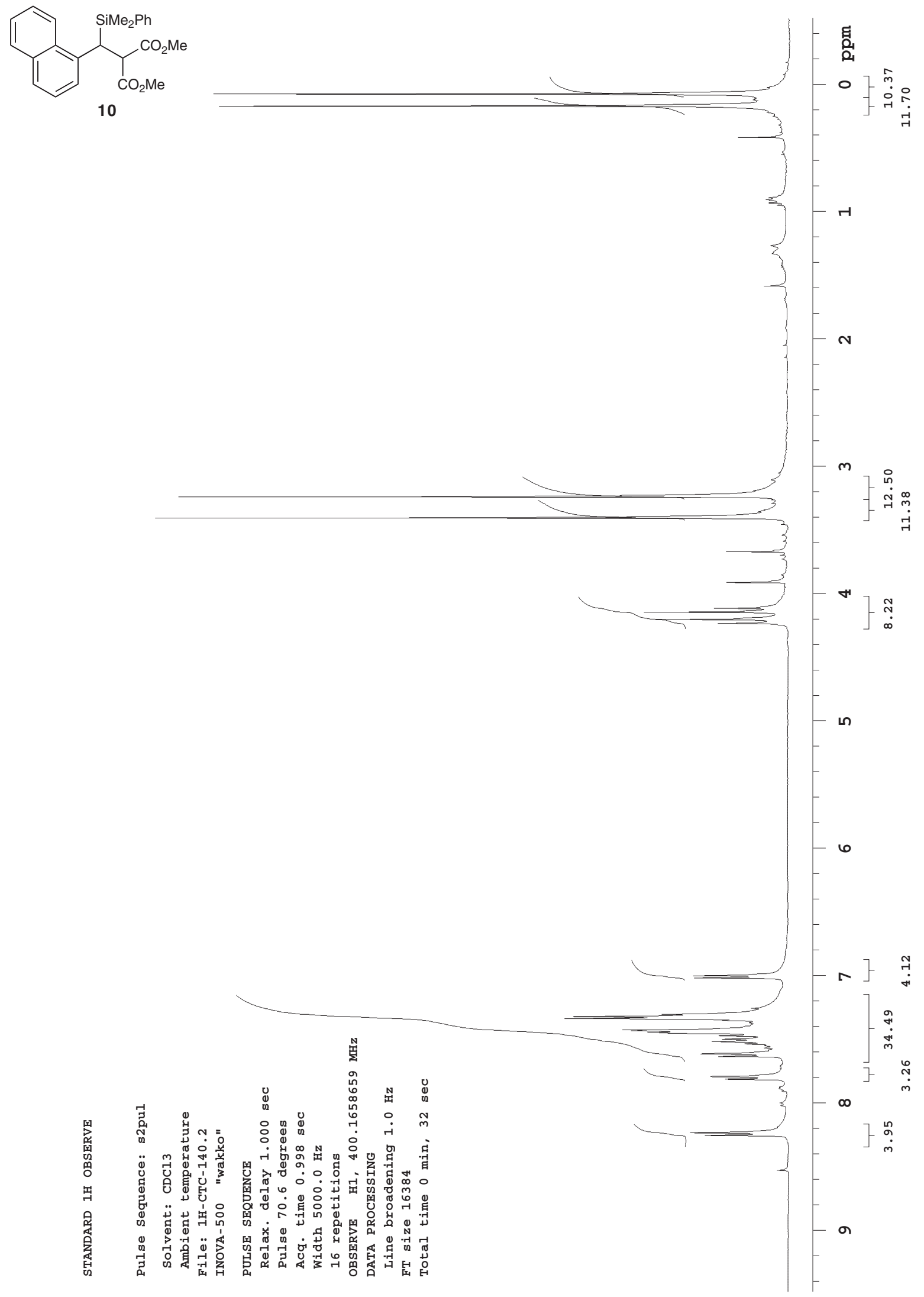
<smiles>CC(=O)OC(C(=O)O[Na])C(C(=O)O)c1ccc2ccccc2c1</smiles>

目

11

$\circ$ f

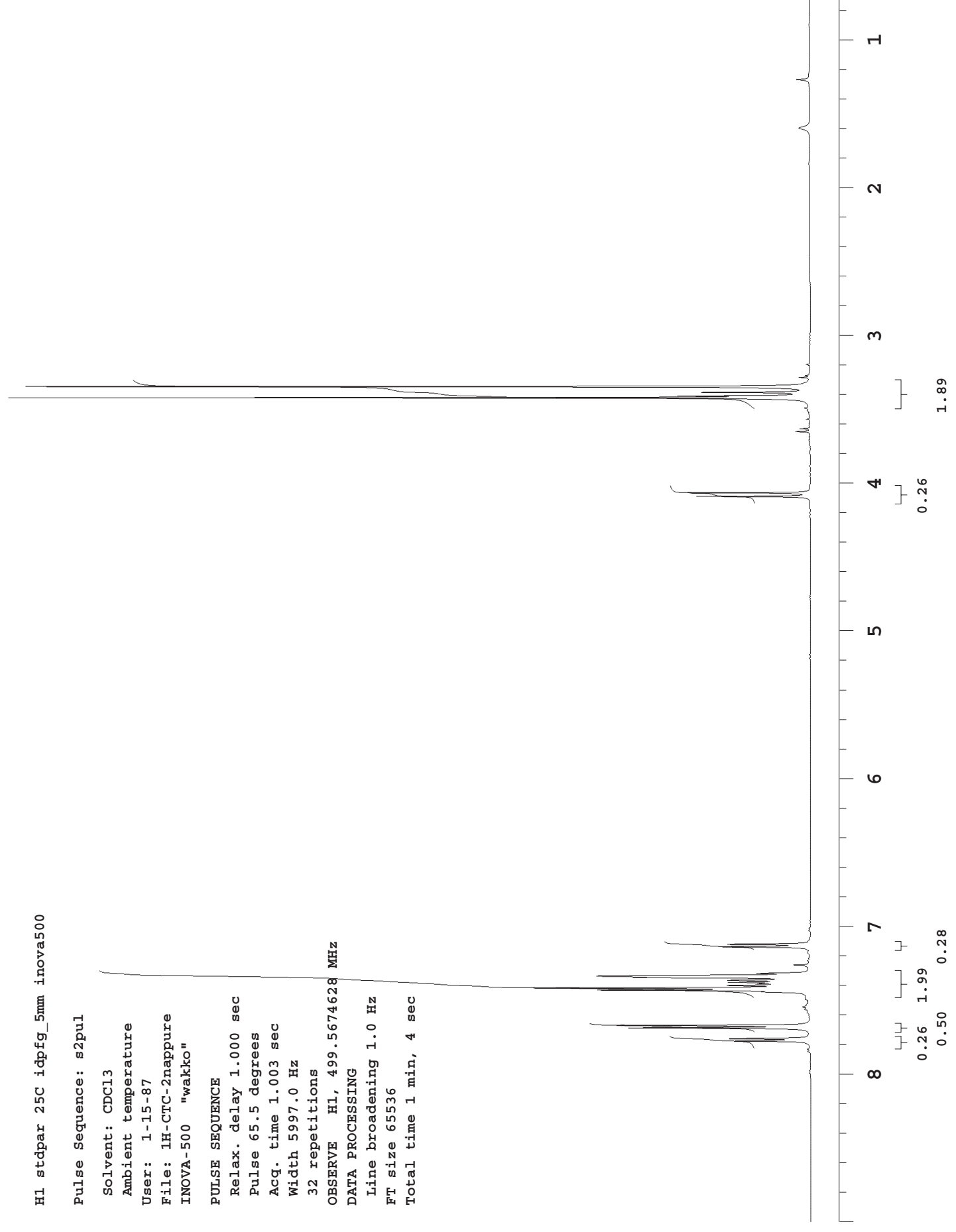




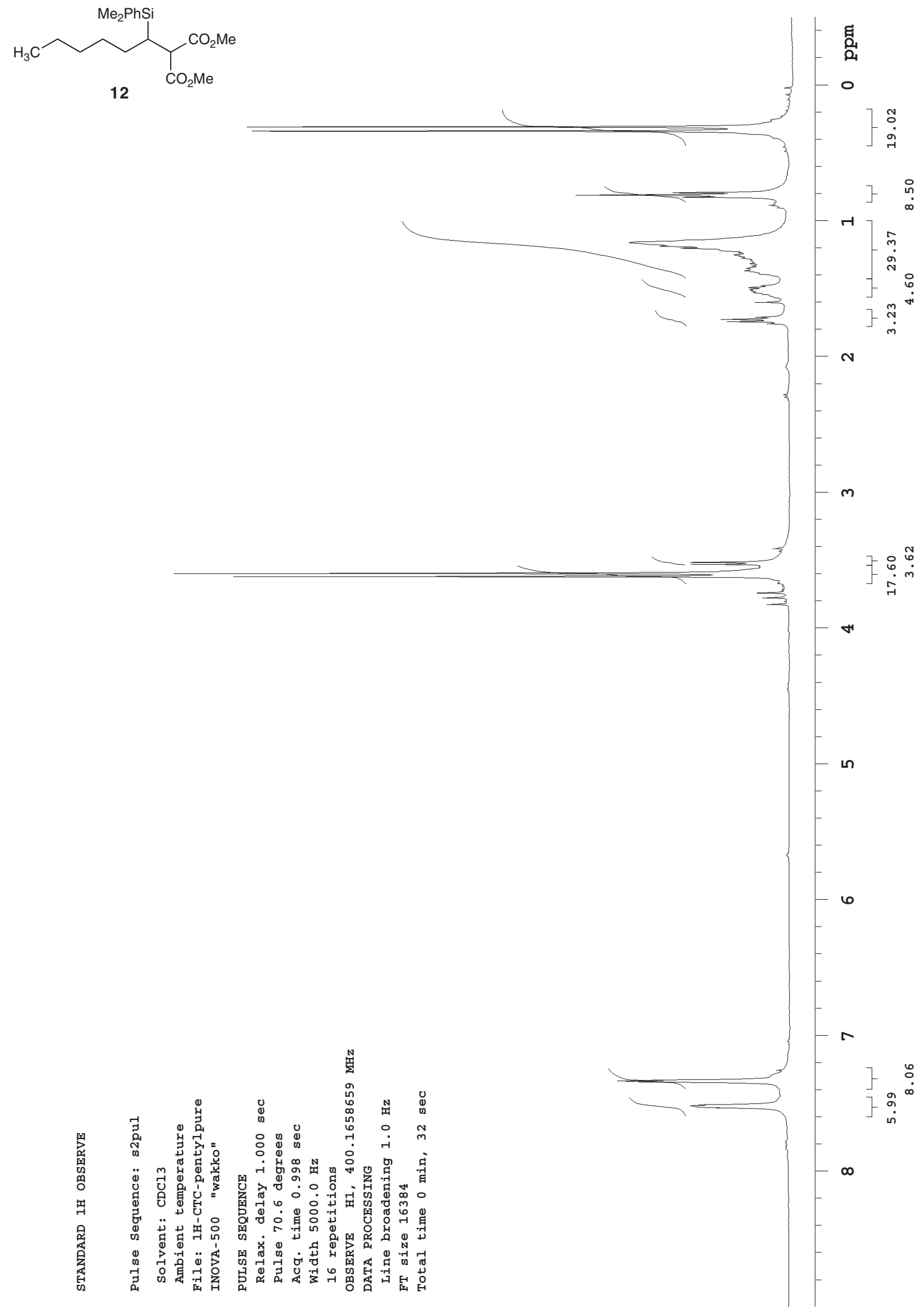



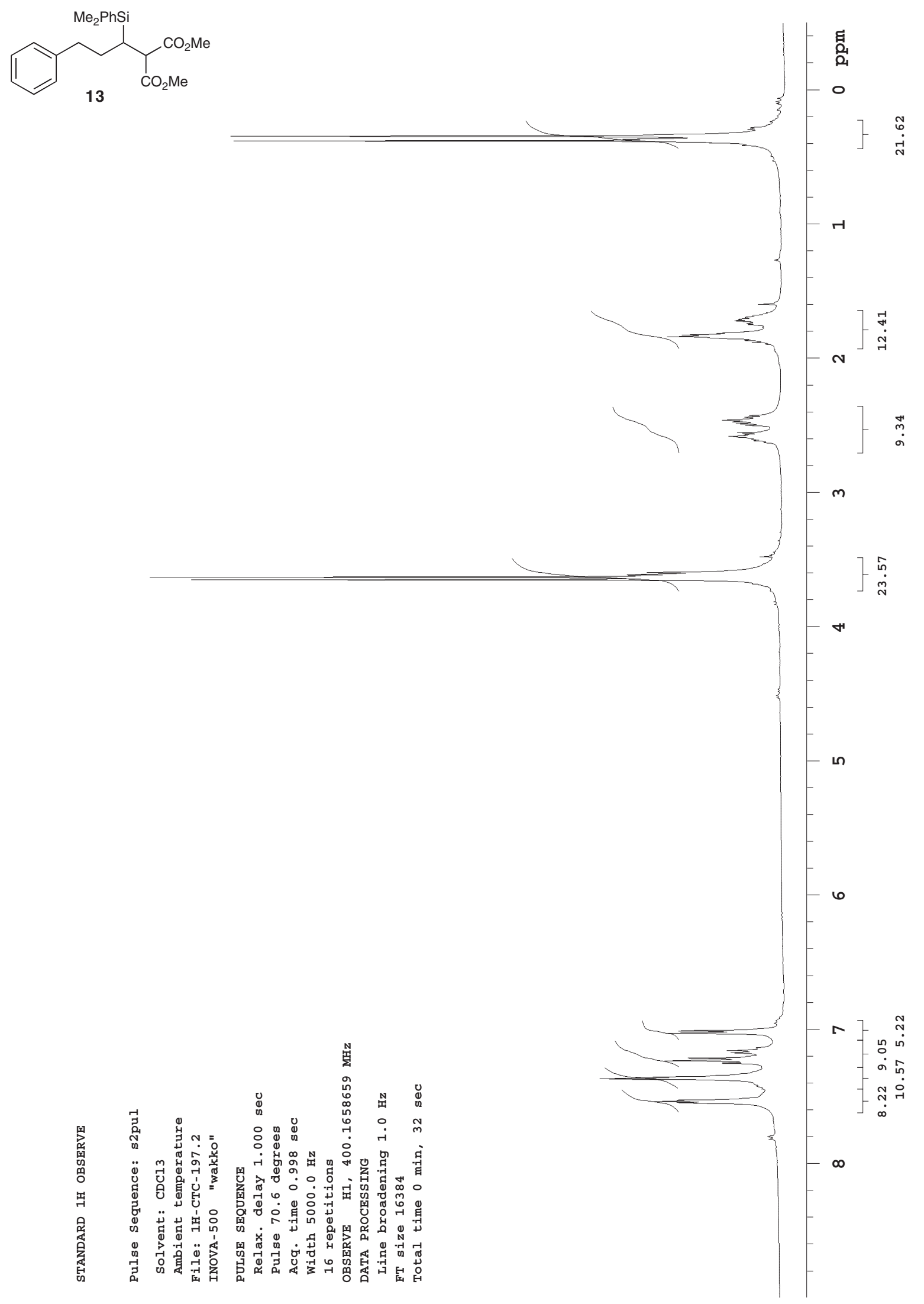


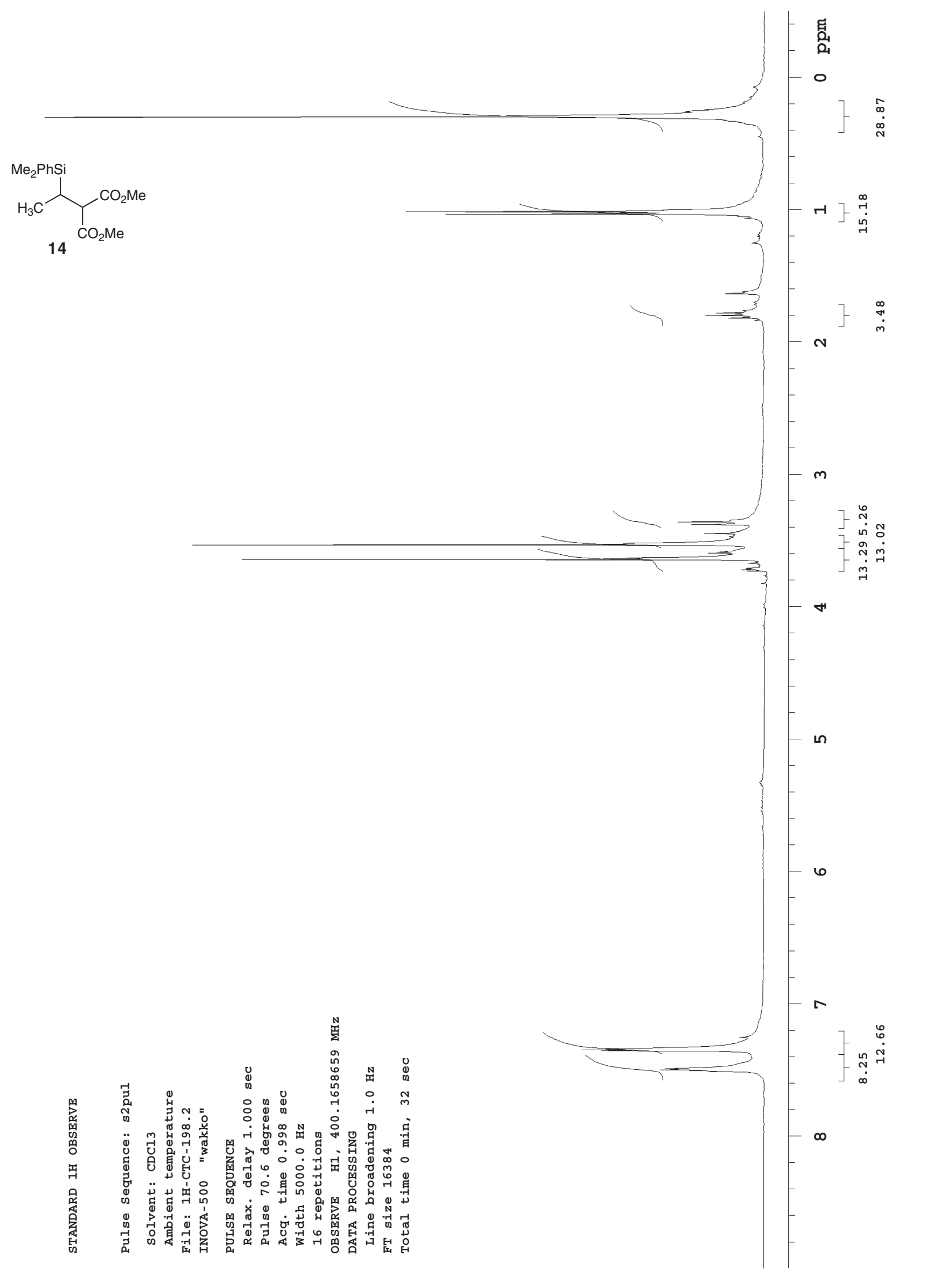


<smiles>CC(=O)OC(C(C)=O)C(NC(=O)C(F)(F)F)C(=O)O</smiles>

15
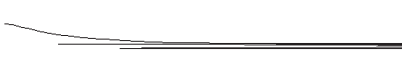

息

年

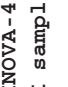

总嵒

$7 \quad 0 \quad 0 \quad 0$

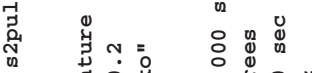

䍃

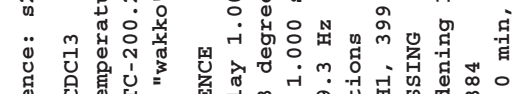

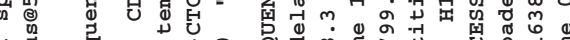

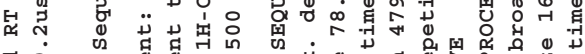

चु

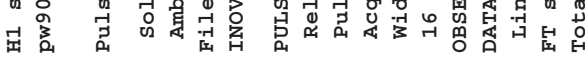

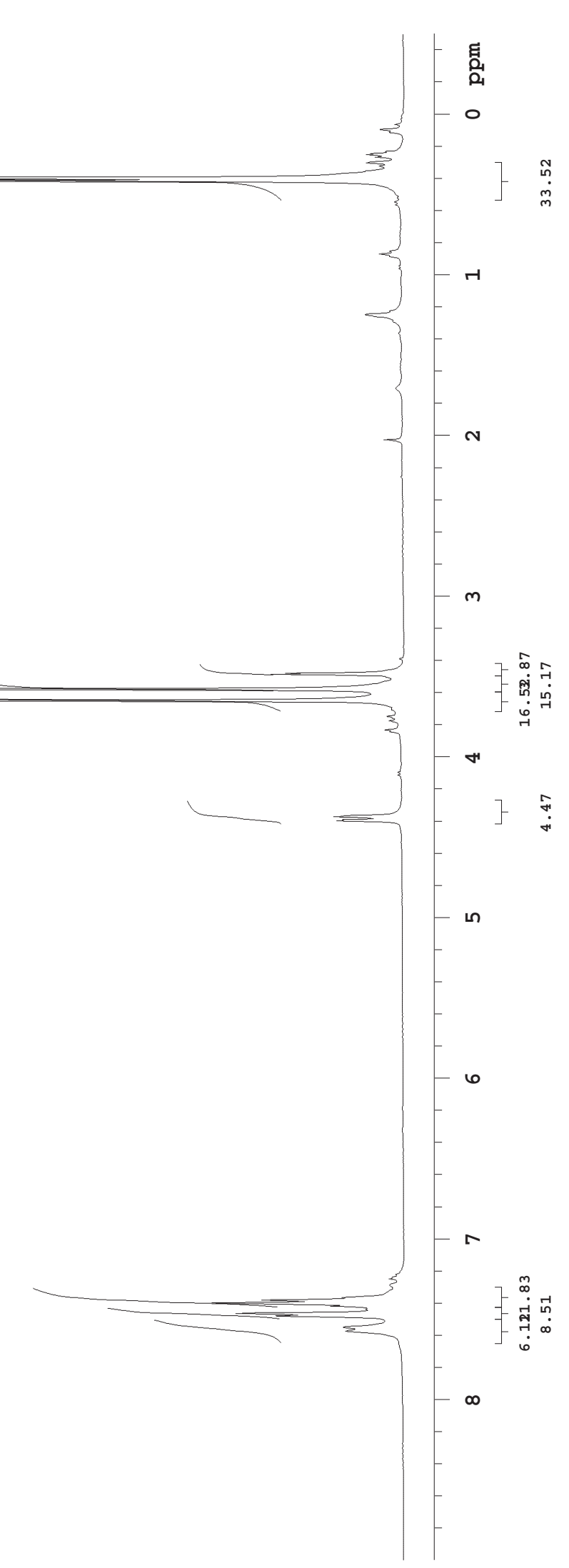




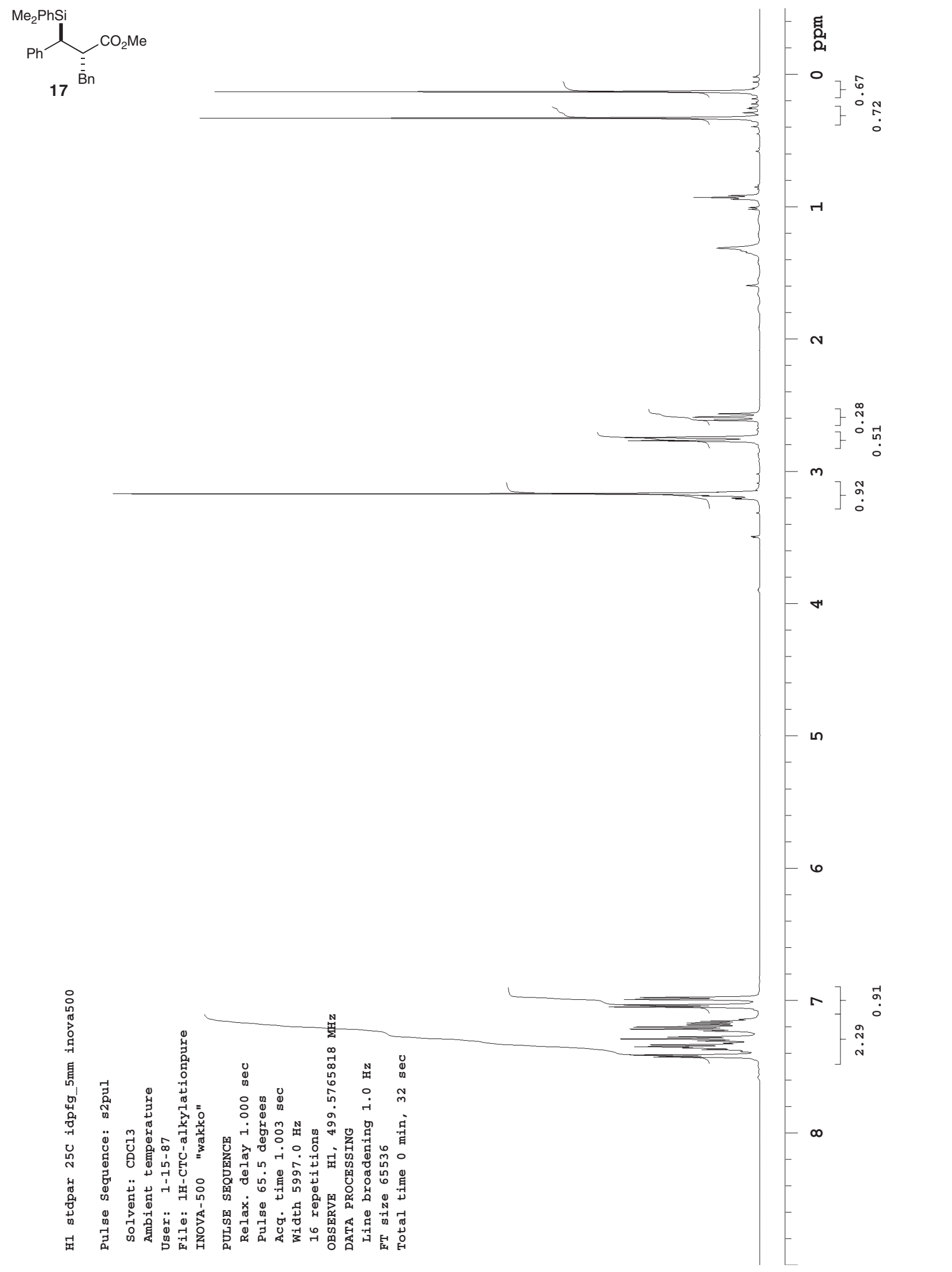

